\title{
The impact of asthma on the gastrointestinal tract (GIT)
}

\author{
This article was published in the following Dove Press journal: \\ Journal of Asthma and Allergy \\ 8 September 2010 \\ Number of times this article has been viewed
}

\section{Warren Antonio Vieira Etheresia Pretorius}

Department of Anatomy, School of Medicine, Faculty of Health Sciences, University of Pretoria, Pretoria, South Africa
Correspondence: Etheresia Pretorius Faculty of Health Sciences, BMW Building, PO Box 2034, University of Pretoria, Pretoria, South Africa Tel +27 I2 319 2533

Fax +27 I2 3192240

Email resia.pretorius@up.ac.za
Abstract: The gastrointestinal tract (GIT) of vertebrates is composed of several distinct compartments and glands as well as an extensive mucosal surface. Its primary function is that of chemical and physical digestion of food and the absorption of nutrients; however, due to its continual antigen exposure, the GIT also has an important defensive immunological function. The GIT's immunological participation is facilitated by the mucosa-associated lymphoid tissues, thought to share the mucosal immunological system with the respiratory mucosa-associated lymphoid tissues. As a result of this shared mucosal immunity, it has been hypothesized that bronchial asthma may be able to affect the body's GIT in the same pathophysiological manner as the airways and lungs. Here we discuss the link between bronchial asthma and pathophysiological features in the GIT - including leukocyte influx, goblet cell alterations, fibrosis, and epithelial and villous atrophy.

Keywords: fundus, pylorus, common mucosal system, asthma, gastrointestinal tract

Within the vertebrate body the gastrointestinal tract (GIT) plays numerous vital roles, including the digestion of food, the absorption of nutrients and water, and the formation of feces for elimination. ${ }^{1,2}$ Another essential role of the intestines is immune defense due to continual exposure to various antigens, both harmless and pathogenic, from the vertebrate's consumed food and resident, commensal organisms. Its immunological participation is facilitated by the GIT's mucosa-associated lymphoid tissues. ${ }^{3-5}$ This tissue is thought to be connected to the respiratory system, as will be explained below, by means of the mucosal immunological system. The examination of the GIT amongst asthmatics has shown various pathological alterations, some of which correlate to that seen in the respiratory system, under similar conditions, and may have arisen due to bronchial asthma using the mucosal immunological system as a means of affecting this region of the body. In this review we will assess the connection that may allow for this process to arise, as well as the documented alterations identified within the GIT of asthmatics.

This review was construed based upon articles and reviews found through Medline, PubMed, Science Direct, and Scopus using various search terms including asthma, GIT, GALT, stomach, intestines, and pathophysiological effects.

\section{The common mucosal system}

The gut associated lymphoid tissue (GALT) is the specialized barrier with which the mucosal immune system is associated within the GIT., ${ }^{2,4}$ The lymphoid tissue of this organ is present in the GIT as diffuse lymphocytic infiltrate or large nonencapsulated aggregations, such as Peyer's patches. ${ }^{2}$ It is exposed continually to antigens, which it 
must determine the nature of - either harmless (such as food and commensal organisms) or dangerous (pathogens) - so as to protect the body from the external environment. ${ }^{4,5}$

The mucosa-associated lymphoid tissues are resident not only in the GIT but also within the respiratory tissues. Both the respiratory tissues and GIT-associated mucosal surfaces have numerous common morphological and functional characteristics, with the mucosal immunological system believed to be one such common feature. ${ }^{3}$

The mucosal immune system comprises of three lines of defense:

1. The non-specific first line defense system - that is the epithelium cells which essentially act as a sieve with the aim of preventing foreign, unwanted antigens from penetrating the mucosa. ${ }^{4}$

2. The innate defense system - that being composed of natural killer cells, macrophages, and epithelial cells. ${ }^{4}$

3. The adaptive immune defense system - composed of the lamina propria, lymphocytes, and Peyer's patches. ${ }^{4}$

Animal experiments have proven that selective trafficking of lymphocytes occurs between these two mucosal surfaces, with migration being facilitated through the lymphatic and circulatory systems that connect the body's various glandular and mucosal sites. ${ }^{5}$ Although this process has been demonstrated within numerous animal studies, little data exist to support its occurrence in humans. Human B and $\mathrm{T}$ lymphocytes, macrophages, and mast cells do appear to communicate between lymphoid populations of mucosal tissues; for example, activated lymphocytes have been shown to circulate between the mucosal tissues of the lungs, salivary glands, and GIT in human asthmatics. , $^{3,5,6}$

It is subsequently hypothesized that this connection in mucosal immunity of the body causes bronchial asthma to affect the entire body's mucosal system, in turn giving rise to the same pathophysiological features associated with asthma in the respiratory tissues in the GIT. ${ }^{5,6}$ Hypoxemia, hypercapnia development, microcirculatory alterations, and endocrine impairment within the GIT are some of the pathophysiological features that have been reported amongst suffers of the disease, helping to validate this hypothesis. ${ }^{7}$ Scientific literature, in terms of this topic, constitutes only a few studies but appears to support the hypothesis that a link exists between bronchial asthma and the GIT. Further research on this topic would greatly help to validate and to understand the already existing, although limited, knowledge available.

The two compartments of the GIT which have been examined within the literature under asthmatic conditions, are the stomach, which holds acidic gastric contents and facilitates a churning action to reduce the ingested bolus to acidic chyme, and the small intestine, the essential absorption and digestive unit of the GIT. The large intestine, participating in water absorption, final digestion, and the formation of feces, does not appear to have been assessed under asthmatic conditions within literature. ${ }^{1,2}$ Table 1 summarizes the overlapping pathological features described in scientific literature

Table I The overlapping pathological features, ascribed to asthma, within different regions of the body, namely the lungs and airways, the small intestine, and the stomach, of humans

\begin{tabular}{|c|c|c|c|}
\hline $\begin{array}{l}\text { Phenomena ascribed } \\
\text { to asthma }\end{array}$ & Lungs and airways & Small intestine & Stomach \\
\hline Cellular atrophy & $\begin{array}{l}\square \\
\text { Surface epithelium }\end{array}$ & $\begin{array}{l}\square \\
\text { Surface, pit, crypt, and } \\
\text { glandular epithelium }\end{array}$ & $\begin{array}{l}\square \\
\text { Surface, pit, crypt, and } \\
\text { glandular epithelium }\end{array}$ \\
\hline Fibrosis & $\nabla$ & 曰 & $?$ \\
\hline $\begin{array}{l}\text { Increased cellular factor } \\
\text { presence }\end{array}$ & $\begin{array}{l}\square \\
\text { Numerous pro-inflammatory } \\
\text { factors including IL5/I } 3\end{array}$ & $\begin{array}{l}\text { V } \\
\mathrm{IL}-5 / / 3 \text { and CMCSF }\end{array}$ & $?$ \\
\hline $\begin{array}{l}\text { Increased leukocyte } \\
\text { infiltration }\end{array}$ & $\begin{array}{l}\text { Vosinophils, lymphocytes, mast } \\
\text { cells, monocytes/macrophages, } \\
\text { and neutrophils }\end{array}$ & $\begin{array}{l}\square \\
\text { Eosinophils, lymphocytes, } \\
\text { and mast cells }\end{array}$ & $\begin{array}{l}\square \\
\text { Lymphocytes }\end{array}$ \\
\hline $\begin{array}{l}\text { Mucus composition } \\
\text { alterations }\end{array}$ & $\begin{array}{l}\square \\
\text { Goblet cells }\end{array}$ & $?$ & $\begin{array}{l}\square \\
\text { Fundic surface } \\
\text { epithelium }\end{array}$ \\
\hline $\begin{array}{l}\text { Thought to be a T-cell } \\
\text { mediated disease }\end{array}$ & $\nabla$ & 甲 & $?$ \\
\hline
\end{tabular}

Note: $\square=$ present, ? = unknown. 
between the body's lungs and airways, stomach, and small intestines, which will be discussed in detail below.

\section{The effects of asthma on the stomach}

The stomach of asthmatics has been observed as undergoing various structural and histological alterations.

\section{Cellular atrophy}

When undiluted, the stomachs mucosa and submucosa are present in a state of prominent longitudinal folds - rugae. These folds allow the stomach the ability to distend and smooth out upon food acquisition, although the stomach's surface still retains an irregular appearance due to the surfaces subdivision by grooves - gastric areas. ${ }^{1,2,8,9}$ These gastric areas possess pits or floveolae, in to which three to seven gastric glands open. ${ }^{8}$ The cardia, situated at the entrance of the stomach from the esophagus, and pylorus, the terminal funnel-shaped region of the stomach, have similar histology in term of their gastric glands. Both are rich in simple or branched tubular mucosa mucus-secreting glands, which open into the floveolae..$^{2,8,10}$ The mucosa of the fundus and corpus possess straight, tubular gastric glands, although they may also possess basal branching glands. ${ }^{2,9}$

Simple columnar epithelial cells, each with basal oval nuclei and mucin droplets, cover the luminal surface of the stomach. ${ }^{9}$ They participate in protecting the stomach from self-digestion from the stomach's own proteolytic and acidic secretions. ${ }^{2,8}$

A light microscopic study has revealed that the stomach undergoes degeneration processes as well as surface, pit, crypt, and glandular epithelium atrophy. ${ }^{7}$ Erosive lesions have been reported in the stomach's mucosa, found in conjunction with parietal cell hyperplasia and hyperfunctioning; parietal cells being responsible for the stomachs hydrochloric acid production and secretion. ${ }^{2,7-9}$ It is believed that the lesions arise as a result of a gastrin-induced event whereby the stomach's parietal cells are overstimulated though an overproduction of histamine by ECL and mast cells. ${ }^{7}$

\section{Hemodynamic alterations}

The lamina propria and submucosa of the stomach are rich in blood vessels which provide the necessary metabolites as well as waste-product, absorbed nutrient, and metabolite removal services. They also provide the stomach with the necessary regulating factors, for the regulation of the mucosal glands secretary activities. ${ }^{1,2,8,9}$
The bronchial blood vessels of asthmatics undergo numerous alterations, including angiogenesis, hypertrophy, and vasodilation. ${ }^{1-13}$ Numerous vasoactive biomolecules have been identified as possible candidates for these hemodynamic alterations within the respiratory tissues of asthmatics, including histamine, interleukin-8 (IL-8), and, of particular importance in facilitating angiogenesis, vascular endothelial growth factor (VEGF). ${ }^{11,14,15}$ Hemodynamic alterations, primarily within in the gastric folds where the endothelium reveals a heterogeneous structure, have been reported amongst asthmatics. ${ }^{7}$ Further research is required to determine whether or not these stomach hemodynamic alterations are facilitated by the same vasoactive biomolecules as in the respiratory systems of asthmatics.

\section{Leukocyte influx}

Due to the stomach's continual exposure to antigens, it plays an essential role in the body's immune defense. The GALT of the stomach, like that of the rest of the GIT, is essential in preventing harmful antigen uptake while still allowing the absorption of nutrient molecules. ${ }^{16}$ The GALT of the stomach is composed of numerous parts including diffuse lymphatic tissues, intraepithelial lymphocytes, epithelium, and eosinophils. Lymphatic nodules have been identified in human and animal tonsils, ileum, and appendix but their presence in the stomach has not been studied in-depth. ${ }^{17}$ The cardiac glandular region of the Bactrian camel's stomach has been reported to hold lymphatic nodules, while Eroschenko (2005) has documented the occasional presence of human fundic and pyloric lamina propria sub-glandular lymphoid nodules. ${ }^{17}$ All the lymphoid elements, responsible for controlling immune responses, are composed of $\mathrm{T}$ and $\mathrm{B}$ lymphocytes. Eosinophils, due their prominent recruitment to the body's GIT under control conditions, are a common infiltrating leukocyte of the stomach. ${ }^{18,19}$

A defining histopathological feature of the respiratory tissues amongst asthmatics is the increased infiltration of leukocytes, predominantly eosinophils and allergenspecific clusters of differentiation (CD) $4^{+} \mathrm{T}$ helper (Th) 2 cells. ${ }^{4,13,14,20-24}$ The entire stomach's mucosa, as in the respiratory tissues, during asthma has been noted to show an increased influx of lymphocytes; however, no researchers to date have determined if these invading lymphocytes are allergen-specific $\mathrm{CD}^{+}{ }^{+} \mathrm{Th} 2$ cells. $^{7}$ As enhanced leukocyte infiltration into a vascularized tissue is a common feature of inflammation, the stomach of asthmatics may be in a state of inflammation. ${ }^{20,25}$ 


\section{Mucus production alterations}

Goblet cell hyperplasia and increased mucus production is commonly described within the airways of asthmatics along with an alteration in the composition of the released mucus. ${ }^{12,26,27}$ Under asthmatic conditions, mucin protein expression appears to be altered, with the mucus itself being found to be more adhesive and less fluid in nature. ${ }^{12-14,27,28}$

The fundal surface epithelium mucin granules have been seen to possess a polymorphic nature based upon the severity of the individual's asthma. Severe to moderate asthmatics possess mucin granules with an electron transparent nature when viewed under a TEM while mild to moderate asthmatics' mucin granules possess a osmophilic nature. ${ }^{7}$ Moderate to severe asthmatics hold a large number of mixt-cells, in possession of a large number of mucin granules, within their fundal glands. The occurrence of these mixt-cells may either be the result of delayed glandular differentiation or the inhibition of protein synthesis due to stomach degeneration and emergency compensation through increased mucus production. ${ }^{7}$ In the pylorus, on the other hand, surface epithelium cells possess round, electron dense granules and, within moderate asthmatics, hyperplasia of its endocrine cells. ${ }^{7}$

\section{The effects of asthma on the small intestine}

The entire small intestinal mucosa of asthmatic humans has been shown to undergo architectural abnormalities and cytokine production alterations similar to those in the bronchial mucosa during asthma as well as being reminiscent of the pathology associated with gluten-sensitive enteropathy (GSE). ${ }^{5}$

\section{Blood vessel alterations}

The lamina propria and submucosa of the small intestine, as in the stomach, are rich in blood vessels which provide the necessary metabolites as well as waste products and absorbed nutrients, such as amino acids and monosaccharides derived from protein and carbohydrate catabolism, respectively, at this absorption site, removal services. ${ }^{1,2,8,9,29}$ They also supply agents which help to regulate the small intestine's digestive functions. ${ }^{1,2,8,9}$

Bronchial blood vessels of asthmatics undergo numerous alterations, including angiogenesis, hypertrophy, and vasodilation. ${ }^{11-13}$ Numerous vasoactive biomolecules have been identified as possible candidates for these hemodynamic alterations within the respiratory tissues of asthmatics, including histamine, IL-8, and, of particular importance, VEGF. ${ }^{11,14,15}$ The villi's microcirculatory beds present an endothelium of a heterogeneous nature under asthmatic conditions. ${ }^{7}$ Further research is required to determine whether or not these intestinal hemodynamic alterations are facilitated by the same vasoactive biomolecules as in the respiratory systems of asthmatics.

\section{Cytokine alterations}

IL-5 and IL-13 are found at increased levels within the mucosa of asthmatic airways compared to those of nonasthmatics. ${ }^{30,31}$ An increase in the mucosa's IL-13, IL-5, and cellular macrophage colony stimulating factor (CMCSF) content has also been identified in the GIT's lamina proprias eosinophil granules and mast cells cytoplasmic granules. ${ }^{5}$ Whether these eosinophils and mast cells are derived from the asthmatic respiratory system, via the common mucosal immune system, or arise in the small intestine itself, due to the surrounding possibly inflammatory stimuli, is unknown. Interestingly, the lymphocytes of the GIT are unable to express these cytokines, although the bronchi can. It is speculated that this difference between the GIT and bronchi lymphocytes may be due to exposure to different cytokine microenvironments at these two distinct mucosal sites, resulting in different cytokine expression by the lymphocytes. ${ }^{5}$ The role of IL-13, IL-5, and CMCSF in the intestine during asthma is unknown; however, they are involved in eosinophil survival, proliferation, and function as well as in modulating the body's immune responses at mucosal sites. ${ }^{5}$

\section{Fibrosis in the lungs and GIT}

Fibrosis can be defined as an incorrectly regulated wound healing process, commonly facilitated by chronic inflammation as a result of repeated injury and repair processes occurring. ${ }^{32}$ Myofibroblasts are the most important cellular participants in this, traditionally considered, $\mathrm{CD} 4^{+} \mathrm{Th} 2$ cell cytokine system. The importance of these fibroblastic cells, located within the body's granulation tissues, is related to that fact that they are able to produce and control a majority of the factors and functions specific to the disease. ${ }^{32}$

Fibrosis via the accumulation of sub-epithelial myofibroblasts is a prominent feature of asthmatic airway remodeling. ${ }^{12,14}$ This process can affect the structure of the airways through the secretions of various growth factors, inflammatory molecules and ECM elements by the myofibroblasts themselves. ${ }^{12}$ 
Moderate diffuse fibrosis may be present within the small intestine of asthmatics. ${ }^{7}$ Its presence is understandable in the GIT as fibrosis commonly occurs in response to inflammation, which would appear to be present in the GIT of asthmatics due the feature of increased leukocyte influx, and may even contribute to furthering this inflammatory state. ${ }^{32,33}$

\section{Leukocyte infiltration}

The body's small intestine is exposed to an array of bacteria, bacterial products, and dietary antigens, which all necessitate the need for correct and efficient immune responses for homeostasis to be maintained. ${ }^{34-36}$ This is achieved through the GALT, with the mucosa of the GIT itself possessing the largest and most complex portion of the body's immune system, with about $75 \%$ of all the body's immune cells being localized to the GIT. ${ }^{35-37}$ The small intestine's GALT possesses lymphoid elements in the form of Peyer's Patches, mesenteric lymph nodes (MLN), and isolated lymphoid follicles. ${ }^{18,35,38}$ These lymphoid elements are composed of T and B lymphocytes; with the intestinal T cell populations being important participants in the mucosal barrier through their sensing of invading bacteria and their secreting of cytokines for the regulation of other infiltrating immune cells. ${ }^{18}$ The effecter cells, regulated by the intestinal lymphocytes, are situated in the mucosa too and comprise lymphocytes, dendritic cells, macrophages, neutrophils, granulocytes, and mast cells. ${ }^{18,34}$

Intestinal macrophages constitute about $10 \%-20 \%$ of all the mononuclear cells in the intestinal lamina propria as well as being the largest collection of macrophages in the body. ${ }^{36}$ They are continually recruited from blood monocytes and show a larger population size within the small intestine in comparison to the large intestine. ${ }^{35,36}$ Tissue macrophages are known to be essential in maintaining homeostasis by participating in the removal of altered cells, tissue remodeling, repair, and inflammation. The intestinal macrophages, though, are unlike other tissue macrophages, showing only minimal inflammation capabilities and are incapable of acting as professional antigen presenting cells. ${ }^{36}$ It is believed that this nature of intestinal macrophages is the result of their co-evolution with their host's intestinal flora so as to diminish continual stimulation of inflammation and thus maintain local tissue homeostasis. They have low, or even absent, expression of surface CD48, CD8, and CD86; low levels of proinflammatory cytokine production and are relatively unreceptive to proinflammatory stimuli, for example they do not respond to lipopolysaccharide. ${ }^{35,36}$
They do, however, still act as powerful phagocytic cells, showing potent bactericidal activates. ${ }^{36}$

Under control conditions most of the body's eosinophils are recruited into the GIT's lamina propria, excluding the esophagus. Their levels occur independently of lymphocyte and enteric flora levels, indicating a unique regulation system for their recruitment in comparison to other leukocytes. This regulation is achieved by the continual expression of eoxatin-1 by the GIT, which recruits this leukocyte. ${ }^{19}$

During asthma the bronchial epithelium and lamina propria show infiltration of lymphocytes and eosinophils, and this feature has also been found in the small intestine of asthmatics. Additionally, the intestinal lamina propria has shown increased mast cell infiltration., ${ }^{5,7}$ This infiltration of lymphocytes and mononuclear cells into the lamina propria does not differ between allergic and non-allergic asthmatics although treatment has been seen to induce an effect. Those utilizing oral steroids, when suffering from severe asthma, show significantly lower mast cell and lymphocyte counts than those who utilize inhaled steroids, when suffering from moderate asthma, and those who remain untreated, due to suffering from only mild asthma. ${ }^{5}$ These features would appear to indicate that the small intestine of asthmatics is likely to be in a state of inflammation. ${ }^{20,25}$

Mucosal lesions are seen in GSE, which are mediated by the action of T cells. As bronchial asthma is considered to be a T cell-mediated disease, it has been hypothesized that the lesions present in the small intestine of asthmatics are facilitated by a similar mechanism to that occurring in GSE. ${ }^{5}$

\section{GIT permeability}

Benard et al (1996) revealed, through the utilization of the Chromium ethyleneddiaminetetraacetic acid (CrEDTA) test, that the small intestine of asthmatics showed increased permeability in comparison to that of control patients. The permeability did not differ between allergic and non allergic asthmatics, severity of the disease, or the steroid treatments utilized. ${ }^{6}$ The CrEDTA test is a highly sensitive but low specificity test. This test unfortunately did not reveal the location of the small intestine's permeability, although the involvement of the small intestine's tight junctions has been proposed. ${ }^{6}$ The mechanism for this increased permeability in asthmatics is unknown; it is unlikely that this feature is a result of the common mucosal system as it has not be found to correlate with factors of airway asthma, such as disease severity and treatment utilization. ${ }^{6}$ 


\section{Goblet cell alterations}

Amongst the resident epithelium cells population of the small intestines mucosa, there exists a group of specialized cells known as goblet cells. These cells, although at much lower concentrations than their simple columnar counter parts, provide each villi of the small intestine with a peppered appearance., ${ }^{2,8,9}$ These cells are responsible for the small intestine's mucus production, which protects and lubricates the luminal walls. ${ }^{1,9}$

A characteristic of allergic inflammation seen in the small intestine in Ozdemir et al's 2007 study was that ovalbumin (OVA) sensitized mice showed increased mucus production, facilitated by the mucosa's goblets cells. The goblets cells were noted to increase both in number and size. The mean goblet size in the duodenum was found to roughly double, while that in the jejunum and ileum increased roughly 3 -fold. ${ }^{39}$ Goblet cell hyperplasia and increased mucus production is commonly described within the airways of asthmatics. ${ }^{26}$ The presence of goblet cell hyperplasia in mild and moderate asthmatics has been attributed with roughly a 3 -fold increase in goblet cell number and stored mucus volume in comparison to controls and hence is comparable to that seen in the small intestines of the sensitized mice studied by Ozdemir et al..$^{27,39,40}$ Unfortunately, although comparable, a clear relationship between intestinal goblet cell hyperplasia and hyperfunctioning could not be extrapolated as Ozdemir and coworkers only considered the one-way effect of a food allergen presented intragastricularly that subsequently induced asthma. Whether the process works in the reverse, so that asthma alone induces the same responses in the small intestines goblets cells, was not examined. ${ }^{39}$

\section{Villous atrophy}

The entire small intestine possesses permanent parallel folds, referred to as plica circularis, which are formed by the mucosa and part of the submucosa. Upon each of these folds lie extensions known as villi, constituted by the lamina propria and epithelium of the mucosa. ${ }^{1,2,8,9}$ Upon the mucosa of these extensions lie a large population of simple columnar epithelium cells in the possession of microvilli upon their luminal surfaces. ${ }^{1,2,8,9}$ The plica circularis, villi, and microvilli all contribute to a larger surface area through which nutrient, water, and electrolyte absorption can take place. ${ }^{1,2,8,9}$

In an experimental study with mice given OVA intragastrically and intraperitoneally a significant decrease was found in their villous/crypt ratio - villous atrophy - due to a reduction in villi height as well as an increase in crypt depth. ${ }^{39,41}$ Mice sensitized with OVA only intraperitoneally showed an increase in their villous/crypt ratio, although this process was also suggested to be a proinflammatory response of the mucosa to the antigen. ${ }^{39}$ The mice sensitized by OVA both intragastrically and intraperitoneally, with a predisposition to the antigen, developed allergic airway responses as well. The antigen therefore appears to be taken up by the GIT and presented preferentially to naïve $\mathrm{T}$ lymphocytes in the Peyer's Patches of the small intestine. The $T$ cells would then be primed and subsequently enter the blood stream to travel to other immune mucosal sites, such as that of the respiratory system, or they would remain in the GIT. ${ }^{39}$ However, whether the induction of asthma subsequently facilitate villous atrophy was not assessed. One cannot assume from these results that the induction of asthma first would induce villous atrophy, as the process of villous atrophy may only be a unidirectional event requiring solely gastrointestinal antigen exposure rather than the induction of asthma. Although partial villous atrophy is seen amongst human asthmatics as well as surface, pit, crypt, and glandular epithelium atrophy in the duodenum, it was not stated or even considered if their asthma arose from gastrointestinal antigen exposure(s), as was the case for the mice studied by Ozdemir and coworkers, which creates suspicion as to whether or not the perceived atrophy was a result of intragastricular food allergen exposure. ${ }^{5,7}$

\section{Clinical relevance}

The full clinical relevance of asthma's GIT impact has not been examined within the literature to date. The most likely consequence for asthmatic patients would be impaired digestive and absorption functions as well increased risk of disease contraction. The cellular atrophy noted within the GIT would be a likely means for reduced nutrient digestion and absorption. The undigested and unabsorbed nutrients and electrolytes in the intestines could further more osmotically withdraw fluids from of the intestines inducing diarrhea. ${ }^{42-45} \mathrm{~A}$ further implication of cellular atrophy would be the formation of GIT ulcerations. Increased mucosal permeability described by Benard and coworkers in 1996 would entail increased bacterial and bacterial product uptake. This would subsequently trigger further immune activation and inflammation within the GIT and possibly induce various related diseases. ${ }^{6,44} 48$

\section{Conclusion}

It can be concluded from the above review of literature, that studies conducted so far appear to support the hypothesis 
that a link exists between bronchial asthma and the GIT, particularly when considering features such as increased leukocyte infiltration, goblet cell alterations, fibrosis, and cytokine alterations, which are characteristic of asthmatic airways and lung tissues. Unfortunately, our understanding of this asthma-GIT relationship is still limited. Further research is required in order to completely validate the suggested hypothesis and make sure that the perceived results are not the result of ingested food allergens, as may have been the case in the study by Ozdemir and coworkers.

\section{Disclosure}

The authors report no conflicts of interests in this work.

\section{References}

1. Gartner LP, Hiatt JL. Color atlas of histology. 2nd ed. Baltimore: Williams \& Wilkins; 1994.

2. Wheater PR, Burkitt HG, Daniels VG. Functional histology. 2nd ed. Edinburgh: Churchill Livingstone; 1987.

3. Rudzik R, Clancy RL, Perey DYE, Day RP, Bienenstock J. Repopulation with IgA-containing cells of bronchial and intestinal lamina propria after transfer of homologous Peyer's patch and bronchial lymphocytes. J Immunol. 1975;114:1599-1604.

4. Nauta AJ, Engels F, Knippels LM, Garssen J, Nijkamp FP, Redegeld FA. Mechanism of allergy and asthma. Eur J Pharmacol. 2008;585:354-360.

5. Wallaert B, Desreumaux P, Copin MC, et al. Immunoreactivity for interleukin 3 and 5 and granulocyte/macrophage colony-stimulating factor of intestinal mucosa in bronchial asthma. J Exp Med. 1995;182(6): 1897-1904.

6. Benard A, Desreumeaux P, Huglo D, Hoorelbeke A, Tonnel AB, Wallaert B. Increased intestinal permeability in bronchial asthma. J Allergy Clin Immunol. 1996;97(6):1173-1178.

7. Nepomnyashchikh GI, Chernyavskaya GM, Aidagulova SV. Korabel'nikov DI. Ultrastructural changes in cells of the gastric and small intestinal mucosa during bronchial asthma. Bull Exp Biol Med. 2004;137(3):341-346.

8. Coetzee HL, Loots GP, Meiring JH. Human histology. Pretoria: van Schaik Publishers; 2003.

9. Eroschenko VP. diFiore's atlas of histology with functional correlations. 10th ed. New York: Lippincott Williams \& Wilkins; 2005.

10. Rohrer V. Human gastric mucosa: correlation of structure and function. Am J Clin Nutr. 1971;24:137-143.

11. Wilson JW, Kotsmbos T. Airway vascular remodeling in asthma. Curr Allergy Asthma Rep. 2003;3:153-158.

12. Mauad T, Bel EH, Sterk PJ. Asthma therapy and airway remodeling. J Allergy Clin Immunol. 2007;120(5):997-1009.

13. Sumi Y. Hamis Q. Airway remodeling in asthma. Allergol Int. 2007;56(4):341-348.

14. Warner SM, Knight DA. Airway modeling and remodeling in the pathogenesis of asthma. Curr Opin Allergy Clin Immunol. 2008;8(1):44 48.

15. Walters EH, Soltani A, Reid DW, Ward C. Vascular remodeling in asthma. Curr Opin Allergy Clin Immunology. 2008;8(1):39-43.

16. Awang-Hazmi AJ, Zuki ABZ, Zamri-Saas M, Po Po S. The response of gut associated lymphoid tissues (GALT) flowing oral administration of P.Multocida B2 in rats. Vet On-Line [serial on the Internet]. 2007 [cited 2009 Oct 6]. http://www.priory.com/vet/peyers.htm. Accessed Oct 6, 2009.
17. Wang WH. Observations on aggregated lymphoid nodules in the cardiac glandular areas of the Bacterian camel (Camelus bacterianus). Vet $J$. 2003;166(2):205-209.

18. Coombes JL, Maloy KJ. Control of intestinal homeostasis by regulatory T cells and dendritic cells. Semin Immunol. 2007;19:116-126.

19. Hogan SP, Rosenberg HF, Moqbel R, et al. Eosinophils: biological properties and role in health and disease. Clin Exp Allergy. 2008;38:709-750.

20. Kay AB. Leukocytes in asthma. Immunol Invest. 1988;17:679-705.

21. Lloyd CM, Rankin SM. Chemokines in allergic airway disease. Curr Opin Pharmaco. 2003;3(4):443-448.

22. D'Ambrosio D, Panina-Bordignon P, Sinigaglia F. Chemokine receptors in inflammation: an overview. JImmunol Methods. 2003;273: $3-13$.

23. Gwinn WM, Damsker JM, Falahati R, et al. Novel approach to inhibit asthma-mediated lung inflammation using anti-CD147 intervention. J Immunol. 2006;177:4870-4879.

24. Kelly M, Hwang JM. Kubes P. Modulating leukocyte recruitment in inflammation. JAllergy Clin Immunol. 2007;120:3-10.

25. Rang HP, Dale MM, Ritter JM, Moore PK. Pharmacology. 5th ed. Edinburgh: Churchill Livingstone; 2003.

26. Rogers DF. Airway goblet cell hyperplasia in asthma: Hypersecretory and anti-inflammatory? Clin Exp Allergy. 2002;32: $1124-1127$.

27. Fahy JV. Goblet cell and mucin gene abnormalities in asthma. Chest. 2002;122:320S-326S.

28. Gordon BR. Asthma history and presentation. Otolaryngol Clin North Am. 2008;41(2):375-385.

29. Nelson DL, Cox MM. Lehninger, principles of biochemistry. 4th ed. New York: W. H. Freeman and Company; 2005.

30. Kips JC. Cytokines in asthma. Eur Respir J. 2001;18:S24-S33.

31. Andreadis AA, Hazen SL, Comhair SA, Erzurum SC. Oxidative and nitrosative events in asthma. Free Radic Boil Med. 2003;35(3): 213-225.

32. Lupher ML, Gallatin WM. Regulation of fibrosis by the immune system. Adv Immunol. 2006;89:245-288.

33. Smit JJ, Lukacs NW. A closer look at chemokines and their role in asthmatic responses. Eur J Pharmacol. 2006;533:277-288.

34. Doganci A, Neurath MF, Finotto S. Mucosal immunoregulation: transcription factors as possible therapeutic targets. Curr Drug Targets. 2005;4:565-575.

35. Platt AM, Mowat AM. Mucosal macrophages and the regulation of immune responses in the intestine. Immunol Letters. 2008;119: 22-31.

36. Schenk M, Mueller C. Adaptations of intestinal macrophages to an antigen-rich environment. Semin Immunol. 2007;19:84-93.

37. Bengmark S. Synbiotics and the mucosal barrier in critically ill patients. Curr Opin Gastroenterol. 2005;21:712-716.

38. Langman JM, Rowland R. The number and distribution of lymphoid follicles in the human large intestine. J Anat. 1986;194:189-194.

39. Ozdemir C, Sel S, Schöll I, et al. CD4+ T cells from mice with intestinal immediate-type hypersensitivity induced airway hyperreactivity. Clin Exp Allergy. 2007;37(10):1419-1426.

40. Rogers DF. Airway goblet cells: responsive and adaptable front-line defenders. Eur Respir J. 1994;7:1690-1706.

41. The Center for Cancer Education - Villous atrophy [homepage on the Internet]. Newcastle: University of Newcastle; [updated 2000 Mar 05; cited 2009 Jan 31]. Available from: http://cancerweb.ncl.ac.uk/cgi-bin/ omd?villous+atrophy

42. Ullrich R, Zeitz M, Heise W, et al. Small intestinal structure and function in patients infected with human immunodeficiency virus (HIV): evidence for HIV-induced enteropathy. Ann Intern Med. 1989;111:15-21.

43. Beaugerie L, Carbonnel F, Carrat F, et al. Factors of weight loss in patients with HIV and chronic diarrhea. AIDS Hum Retroviruses. 1998;19:34-39. 
44. Kotler DP. HIV infection and the gastrointestinal tract. AIDS. 2005;19:107-117.

45. Sestak K. Chronic diarrhea and AIDS: insight into studies with nonhuman primates. Curr HIV Res. 2005;3:199-205.

46. Sankaran S, Guadalupe M, Reay E, et al. Gut mucosal T cell responses and gene expression correlate with protection against disease in long-term HIV-1-infected nonprogressors. PNAS. 2005;102: 9860-9865.
47. Guadalupe M, Reay E, Sankaran S, et al. Severe CD4+ T-Cell Depletion in gut lymphoid tissue during primary human immunodeficiency virus type 1 infection and substantial delay in restoration following highly active antiretroviral therapy. J Virol. 2003;77:11708-11717.

48. Kotler DP. Intestinal disease associated with HIV infection: Characterization and response to antiretroviral therapy. Pathobiology. 1998;66:183-189.

\section{Publish your work in this journal}

The Journal of Asthma and Allergy is an international, peer-reviewed open-access journal publishing original research, reports, editorials and commentaries on the following topics: Asthma; Pulmonary physiology; Asthma related clinical health; Clinical immunology and the immunological basis of disease; Pharmacological interventions and
Dovepress

new therapies. Issues of patient safety and quality of care will also be considered. The manuscript management system is completely online and includes a very quick and fair peer-review system, which is al easy to use. Visit http://www.dovepress.com/testimonials.php to read real quotes from published authors.

Submit your manuscript here: http://www.dovepress.com/journal-of-asthma-and-allergy-journal 